\title{
Основные климатические характеристики и особенности их изменения на территории бассейна реки Дебед
}

\author{
В.Г. Маргарян ${ }^{\bowtie}$ \\ Ереванский государственный университет, Республика Армения \\ (0025, г. Ереван, ул. Алека Манукяна, 1)
}

\begin{abstract}
Аннотация: Цель исследования - провести анализ закономерности временных колебаний основных климатических характеристик (годовая температура воздуха и количество осадков) бассейна реки Дебед.

Материальь и методы. В статье использовались методы математико-статистический, экстраполяции, анализа, аналогии, корреляционный, картографический. В качестве исходного материала использовались данные фактических наблюдений за температурой приземного слоя воздуха и количеством осадков бассейна Дебед на территории Армении. Исследование выполнено на 6 метеорологических станциях бассейна реки Дебед по продолжительным рядам данных наблюдений с середины 1960-х годов по 2018 год.

Результаты и обсуждение. Получена тесная корреляционная связь между годовыми значениями температуры воздуха и атмосферных осадков, которую можно использовать на изучаемой территории бассейна. Представлено внутригодовое распределение температуры воздуха, атмосферных осадков и речного стока, изменения среднегодовой температуры воздуха и атмосферных осадков как для всей территории бассейна Дебед, так и для каждой из действующих в настоящее время метеорологических станций.

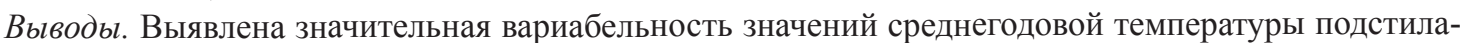
ющей поверхности и годового количества осадков в бассейне реки Дебед. Отмечена повсеместная тенденция к повышению среднегодовой температуры воздуха и преимущественно тенденция к уменьшению годового количества осадков. На некоторых метеорологических станциях наблюдается тенденция увеличения количества осадков. С абсолютной высотой местности обнаружено понижение среднегодовой температуры воздуха.
\end{abstract}

Ключевые слова: бассейн р. Дебед, температура воздуха, атмосферные осадки, многолетние изменения, тренд.

Источник финансирования: Исследование выполнено при финансовой поддержке КН РА (Комитет науки Республики Армения) $u$ РФФИ (Российский фонд фундаментальных исследований) в рамках совместной научной программы 20RF-039 «Краткосрочный вероятностный прогноз стока рек в период весеннего половодья» и № 20-55-05006120 соответственно.

Благодарность. Автор выражает благодарность Михаилу Александровичу Локощенко (МГУ) за консультацию.

Для цитирования: В.Г. Маргарян. Основные климатические характеристики и особенности их изменения на территории бассейна реки Дебед // Вестник Воронежского государственного университета. Серия: География. Геоэкология, 2021, № 4, с. 22-33. DOI: https://doi.org/10.17308/geo.2021.4/3747

\section{ВВЕДЕНИЕ}

Климат планеты за последние десятилетия стремительно меняется - происходит глобальное потепление, на фоне которого возникла проблема оценки макроэкономических последствий изменений климата данной территории [14]. Для лучшего понимания текущих изменений климата не- обходимо выявление долговременных тенденций в ходе основных метеорологических показателей. К сожалению, история инструментальных метеорологических измерений сравнительно недолгая, поэтому важно учитывать все доступные данные измерений в прошлом, которые заслуживают доверия [12].

(C) Маргарян В.Г., 2021

$\varangle$ Маргарян Вардуи Гургеновна, e-mail: vmargaryan@ysu.am

Контент доступен под лицензией Creative Commons Attribution 4.0 License. 
Армения также не осталась в стороне от проблем глобального изменения климата. Согласно 4-ому национальному совещанию [17] об изменении климата на территории республики за период с 1929-1996 годы среднегодовая температура повысилась на $0,4{ }^{\circ} \mathrm{C}$, с $1929-2007$ годы - на $0,85^{\circ} \mathrm{C}$, c 1929-2012 годы - на $1,03{ }^{\circ} \mathrm{C}$, а с 1929-2016 годы - повысилась на $1,23{ }^{\circ} \mathrm{C}$. Среднее количество годовых осадков уменьшилось на 6\% за период с 19351996 годы и около 9 \% - за 1935-2016 годы.

Исследованию стандартных климатических характеристик (температуры воздуха и осадков) посвящены многочисленные научные работы [5, $16,17,18]$. Большой вклад в изучение основных климатических характеристик Армении внесли Г.А. Александрян, А.Б. Багдасарян, В. Г. Маргарян $[12,20,21]$, А.Г. Нерсесян и другие. На четвертом национальном совещании [17] обсуждался вопрос об изменении климата на территории Армении. Данные о температуре воздуха и осадков в республике приведены в ряде климатических справочников $[7,8]$. В этой статье оценивается изменение основных климатических характеристик в бассейне реки Дебед, используя длительный ряд данных инструментальных наблюдений (1964-2018).

Цель настоящего исследования - решить следующие задачи: выявить, проанализировать и оценить особенности распределения изменения основных климатических характеристик за последние 55 лет в бассейне реки Дебед. В качестве основных климатических характеристик приняты температура воздуха приземного слоя и атмосферные осадки.

\section{МАТЕРИАЛЫ И МЕТОДЫ ИССЛЕДОВАНИЙ}

Для решения поставленных задач в качестве теоретической основы в статье использованы опубликованные источники $[1,4,21-23]$. В качестве исходного материала использованы фактические данные «Центра гидрометеорологии и мониторинга» Министерства окружающей среды Республики Армения за 55 лет (1964-2018 гг.), собранные на 6 метеорологических станциях.

В статье применены следующие методы: математико-статистический, экстраполяции, анализа, аналогии, корреляционный, картографический.

Для выявления долгопериодных изменений климата используются модели нестационарного среднего двух видов: линейного тренда и ступенчатых изменений по отношению к базовой стационарной модели. В работах $[6,11]$ было установлено, что модель ступенчатых изменений среднего значения является более эффективной, чем модель линейного тренда. При этом даже предварительный визуальный анализ свидетельствует о том, что модель ступенчатых изменений средних значений больше соответствует структуре ряда, чем модель тренда, хотя и она также может быть статистически значимой [10].

Общую тенденцию изменения количества осадков можно успешно описать с помощью кубического тренда [12].

Бассейн реки Дебед находится на севере Республики Армения (РА), занимая территорию

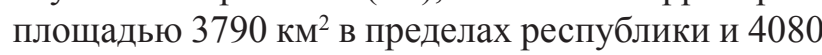
км$^{2}$ за ее пределами. В нижнем течении реки Дебед располагается самая низкая абсолютная высота (375 м) на территории РА. Бассейн отличается расчлененностью рельефа - имеются каньоны, достигающие 300 метров глубины (каньон реки Дебед), и отдельные горные массивы, достигающие более 2500 м высоты. Расчлененность бассейна превышает 2800 м.

Сложное строение рельефа реки Дебед влияет на разнообразие распределения температуры воздуха и атмосферных осадков как в вертикальном, так и в горизонтальном направлениях. На западе бассейн отделяется Джавахкским хребтом. С южной стороны он ограничен Памбакским хребтом. Восточную границу бассейна условно можно провести по водораздельной линии между правыми притоками реки Дебед и Агстев. По направлению к востоку и северо-востоку территория постепенно понижается в сторону долины реки Куры. Между Вирахайоцским (Сомхетским) и Базумским хребтами расположена Лорийская нагорная равнина со средней высотой 1500 метров. Между Базумским и Памбакским хребтами располагается Памбакская котловина. Равнинные части бассейна покрыты черноземными почвами с разнотравной степной растительностью, а на склонах гор с буро-коричневыми и бурыми лесными оподзоленными почвами произрастают лиственные леса.

\section{РЕЗУЛЬТАТЫ И ОБСУЖДЕНИЕ}

На территории бассейна реки Дебед с высоты 451 м до 2066 м, согласно данным фактических наблюдений, средняя годовая температура и годовое количество атмосферных осадков резко изменчивое (табл. 1). За период 1964-2018 годы средняя годовая температура варьирует в диапазоне с $3,7^{\circ} \mathrm{C}$ (Пушкинский перевал) до $12,3{ }^{\circ} \mathrm{C}$ (Баграташен), а годовое количество атмосферных осадков - с 462 мм (Баграташен) до 770 мм (Пушкинский перевал). 
Значения средних годовых температур воздуха и атмосферных осадков за период с 1964-2018 годы на метстанциях в бассейне р. Дебед

[Table 1. Average annual air temperatures and precipitation for the period from 1964-2018 at meteorological stations in the Debed River basin]

\begin{tabular}{|c|c|c|c|c|c|c|}
\hline $\begin{array}{l}\text { Метеорологические станции / } \\
\text { Meteorological stations }\end{array}$ & 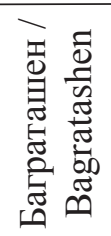 & 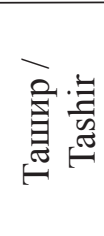 & $\begin{array}{l}\text { 荵志 } \\
\text { 兽 }\end{array}$ & 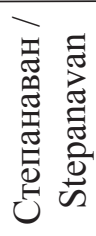 & 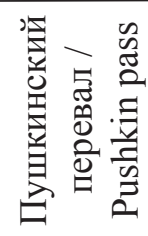 & 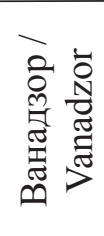 \\
\hline $\begin{array}{l}\text { Высота (м) / } \\
\text { Height (m) }\end{array}$ & 451 & 1507 & 1105 & 1397 & 2066 & 1376 \\
\hline $\begin{array}{l}\text { Температура воздуха }\left({ }^{\circ} \mathrm{C}\right) / \\
\text { Air temperature }\left({ }^{\circ} \mathrm{C}\right)\end{array}$ & 12,3 & 6,2 & 9,5 & 7,3 & 3,7 & 8,3 \\
\hline $\begin{array}{l}\text { Атмосферные осадки (мм) / } \\
\text { Precipitation (mm) }\end{array}$ & 462 & 731 & 547 & 668 & 770 & 566 \\
\hline
\end{tabular}

Наименьшие значения средней месячной температуры воздуха наблюдаются в январе и составляют $-6,35{ }^{\circ} \mathrm{C}$ (Пушкинский перевал), а наибольшие значения - в июле-августе $+23,7-24,0{ }^{\circ} \mathrm{C}$ (Баграташен). Средняя месячная температура переходит положительные значения в марте-апреле, когда устойчиво происходит снеготаяние и половодье в реках бассейна. Сравнительно большое количество осадков отмечается в котловине Лори. Здесь, в Ташире (1507 м), годовое количество осадков составляет 712 мм, а в Степанаване (1397 м) - 658 мм. Количество осадков ументшается в нижнем течении реки Дебед (Баграташен), в долине реки Памбак и в Спитакской котловине (Спитак, 439 мм). Значительная часть осадков выпадает в апреле-июне (35-45 \% от годового количества), минимальное количество наблюдается во второй половине лета и зимой. Количество осадков за летние месяцы пре- восходит количество осадков за зимние месяцы.

С абсолютной высотой местности закономерно понижается годовая температура воздуха и закономерно увеличивается годовое количество осадков. На изучаемой территории за год вертикальный температурный градиент составляет $0,54{ }^{\circ} \mathrm{C} / 100$ м, а вертикальный градиент количества осадков $20 \mathrm{MM} / 100 \mathrm{~m}$.

На рисунке 1 представлено внутригодовое распределение температуры воздуха, атмосферных осадков на метеостанции Степанаван и речного стока водомерного поста Степанаван реки Дзорагет. Как видно из рисунка, при увеличении осадков происходит увеличение речного стока, а при повышении температуры воздуха - наоборот, уменьшение. Однако, весной устойчивый переход температуры через $0{ }^{\circ} \mathrm{C}$ приводит к увеличению речного стока, обусловленное таянием снега, накопленного за зиму.

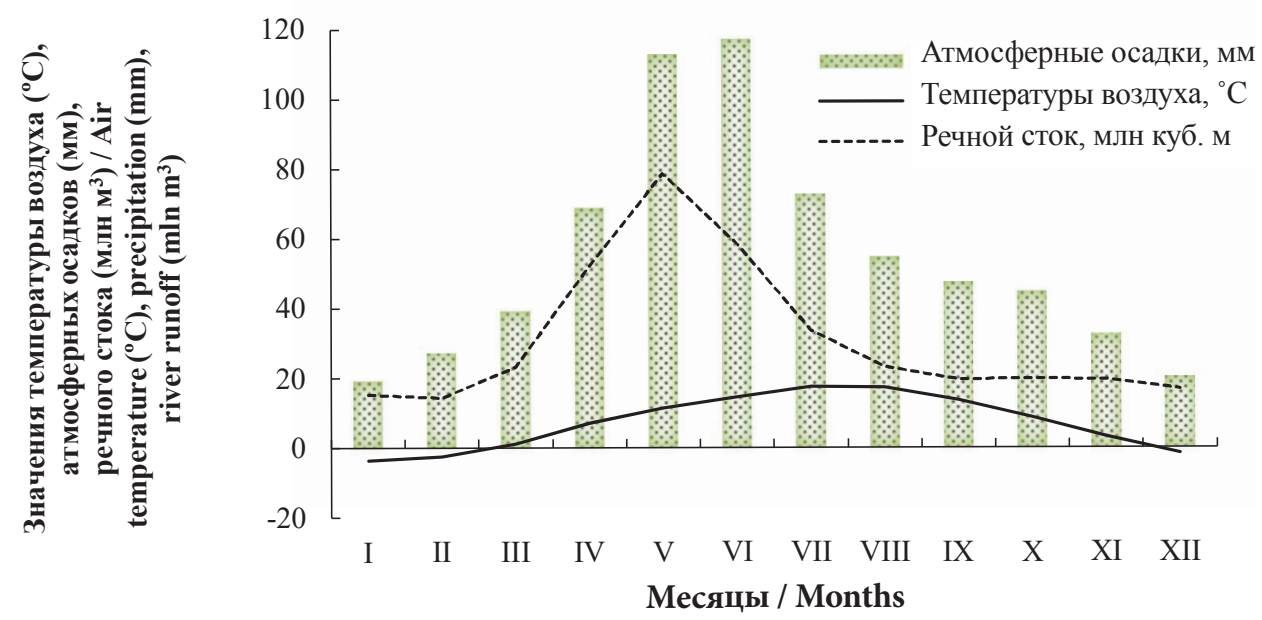

Puc. 1. Годовой ход температуры воздуха и атмосферных осадков метеостанции Степанаван, речного стока р. Дзорагет - п. Степанаван

[Fig. 1. Annual variation of air temperature and precipitation of Stepanavan weather station, river runoff of Dzoraget River - p. Stepanavan] 
В результате расчетов получена тесная корреляционная связь между годовыми значениями температуры воздуха и атмосферных осадков (рис. 2) в бассейне реки Дебед - с увеличением температуры воздуха уменьшаются атмосферные осадки.

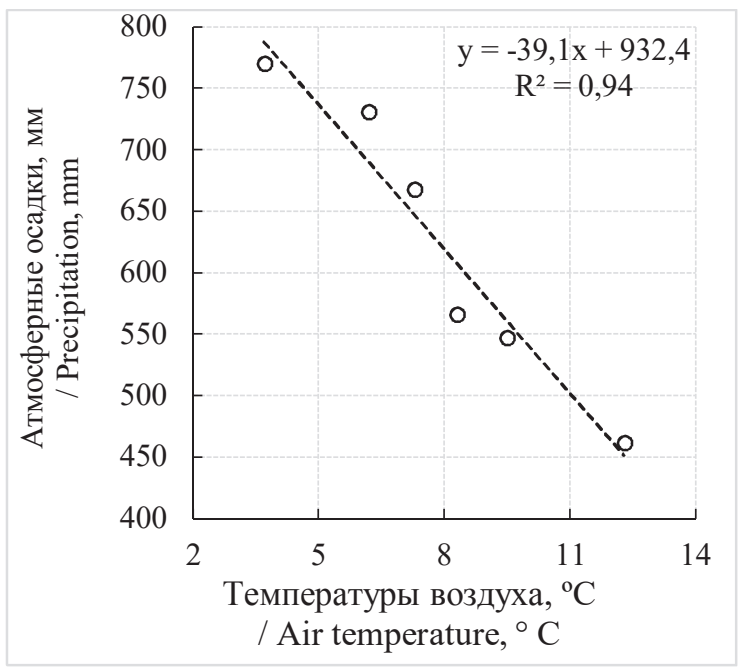

Puc. 2. Корреляционная связь между годовыми значениями температуры воздуха и атмосферных осадков

[Fig. 2. Correlation between annual values of air temperature and atmospheric precipitation]

В статье оценены изменения среднегодовой температуры воздуха и атмосферных осадков как для всей территории бассейна Дебед (рис. 3), так и для каждой из действующих в настоящее время метеорологических станций в отдельности (рис. 4). В бассейне реки Дебед в целом выявлен устойчивый положительный тренд среднегодовой температуры воздуха и устойчивый отрицательный тренд годовой суммы атмосферных осадков. Так как метеорологические станции начинали свою деятельность в разное время (например, метеостанция Пушкинский перевал действует с 1963 года), то средняя температура воздуха за год и годовая сумма атмосферных осадков для сопоставления и сравнения рассчитаны с 1964 года.
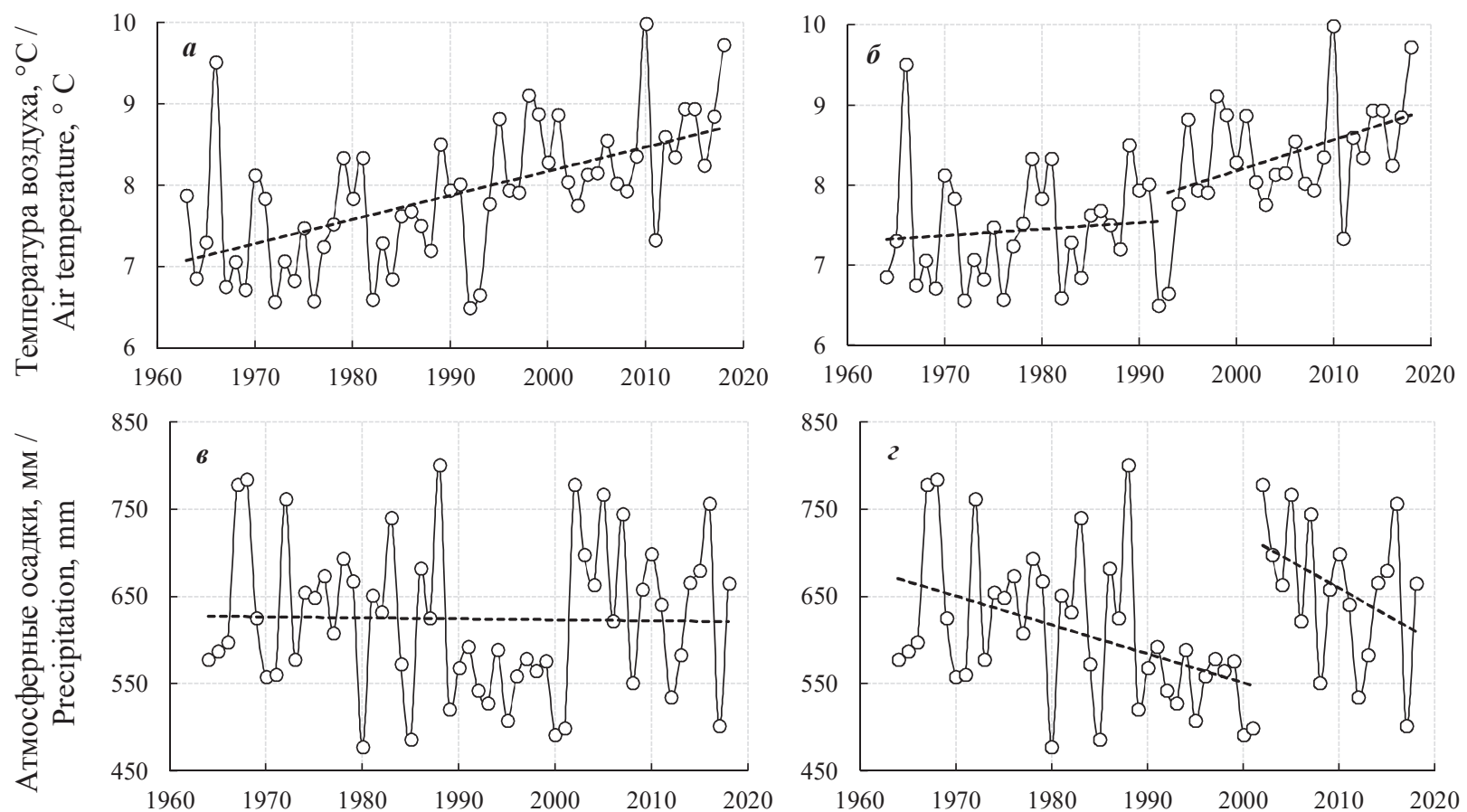

Рис. 3. Многолетние изменения средней температуры воздуха (a, б) и количества атмосферных осадков (в, г) за год в бассейне р. Дебед в целом

[Fig. 3. Long-term changes in the average air temperature (a, b) and the amount of precipitation (c, d) per year in the Debed River basin in general]

Вестник ВГУ, Серия: География. Геоэкология, 2021, № 4, 24-33 
Как следует из рисунка 3 (a, б), линии трендов температуры воздуха положительные. Эта закономерность характерна и для других регионов - Южного Кавказа [18], Восточной Грузии [16], территории высокогорных ландшафтов Северо-Восточного Кавказа [1], Российской Федерации [5], в государствах на территории Европы, ограниченной широтами $40-60^{\circ}$ с.ш. в секторе $0-60^{\circ}$ в.д. [2], Ульяновской области [14], ландшафтам Северного Кавказа [3].

В середине 1990-х четко виден перелом в годовых температурах. Изменения тренда температу- ры воздуха представлены двумя линиями тренда: за период 1964-1992 годы и 1993-2018 годы, которые положительны. Однако, за период 1964-1992 гг. скорость годового потепления $\left(+0,079{ }^{\circ} \mathrm{C} / 10\right.$ лет) меньше скорости годового потепления $\left(+0,389^{\circ} \mathrm{C} /\right.$ 10 лет) за период 1993-2018 гг. Значительный рост годовых температур наблюдается особенно за период 1993-2018 гг. (табл. 2). В среднем по бассейну Дебед с 1964 по 1992 год среднегодовая температура воздуха повысилась на $0,2{ }^{\circ} \mathrm{C}$, a c 1993 по 2018 год - на $1,0^{\circ} \mathrm{C}$, а с 1964 по 2018 год - на $1,7^{\circ} \mathrm{C}$.

Статистические характеристики изменения среднегодовой температуры воздуха

Таблиияа 2 и годовой суммы атмосферных осадков в бассейне р. Дебед

[Table 2. Statistical characteristics of changes in average annual air temperature and annual precipitation in the Debed River basin]

\begin{tabular}{|c|c|c|c|c|c|}
\hline $\begin{array}{c}\text { Периоды / } \\
\text { Periods }\end{array}$ & $\begin{array}{c}\text { Скорость изменения } \\
\text { температуры } \\
\left({ }^{\circ} \mathrm{C} / 10 \text { лет) / }\right. \\
\text { Rate of temperature } \\
\text { change }\left({ }^{\circ} \mathrm{C} / 10 \text { years }\right)\end{array}$ & $\begin{array}{c}\text { Изменения } \\
\text { температуры } \\
\left({ }^{\circ} \mathrm{C}\right) / \\
\text { Temperature } \\
\text { changes }\left({ }^{\circ} \mathrm{C}\right)\end{array}$ & $\begin{array}{c}\text { Периоды / } \\
\text { Periods }\end{array}$ & $\begin{array}{c}\text { Скорость изменения } \\
\text { суммы атмосферных } \\
\text { осадков (мм/10 лет)/ } \\
\text { Rate of change } \\
\text { in precipitation amount } \\
\text { (mm / } 10 \text { years) }\end{array}$ & $\begin{array}{c}\text { Изменения } \\
\text { атмосферных } \\
\text { осадков (мм)/ } \\
\text { Changes } \\
\text { in precipitation } \\
\text { (mm) } \\
\end{array}$ \\
\hline \multicolumn{6}{|c|}{ В целом для всего бассейна р. Дебед / In general, for the entire Debed River basin } \\
\hline 1964 & & & 1964-2001 & $-33,2$ & -126 \\
\hline $1993-2018$ & $+0,389$ & $+1,01$ & $2002-2018$ & $-61,7$ & -105 \\
\hline \multicolumn{6}{|c|}{ На метеостанции Одзун / At the Odzun weather station } \\
\hline 1964-2018 & $+0,288$ & $+1,58$ & 1964-2018 & $-13,3$ & $-73,2$ \\
\hline \multicolumn{6}{|c|}{ На метеостанции Ванадзор / At the Vanadzor weather station } \\
\hline 1964-2018 & $+0,368$ & $+2,02$ & $1964-2018$ & $+10,2$ & +56.1 \\
\hline
\end{tabular}

Начиная с 1993 года, на рассматриваемой территории наблюдается резкое повышение температуры. В бассейне реки Дебед в целом за последние 60 лет сравнительно высокими годовыми температурами (более $9,5^{\circ} \mathrm{C}$ ) характеризуются 1966 , 2010 и 2018 годы, а сравнительно низкими годовыми температурами (менее 6,5-6,6 ${ }^{\circ} \mathrm{C}$ ) - 1972, 1976, 1982, 1992 годы. Наиболее теплыми были 1966 и 2010 годы и на территории высокогорных ландшафтов Северо-Восточного Кавказа [1].

Линии трендов годовой суммы атмосферных осадков отрицательные (рис. 4 - в, г). Выделены два изменения линий трендов: за период 19642001 годов, 2002-2018 годов. Скорость изменения годовой суммы атмосферных осадков за период 1964-2001 годов составила $-33,2$ мм/10 лет, а за период 2002-2018 годы - -61,7 мм/10 лет. За весь период 1964-2018 годы скорость изменения осадков незначительная - -1,02 мм/10 лет (рис. $4-$ в). В среднем по бассейну Дебед уменьшение годо- вой суммы осадков составляет на 126 мм с 1964 по 2001 год, на 105 мм - с 2002 по 2018 год (табл. 2). На территории бассейна реки Дебед в целом за последние 60 лет небольшое годовое количество осадков (менее 500 мм) зарегистрировано в 1980, 1985, 2000, 2016 годах, а максимальное количество осадков (более 750 мм) - в 1967, 1968, 1972, 1988, 2001, 2004, 2015 годах.

В бассейне реки Дебед, согласно данным всех действующих метеостанций, повсеместно отмечается тенденция к повышению среднегодовой температуры воздуха, а за тот же срок в основном регистрируется тенденция уменьшения годового количества осадков. Только на некоторых метеостанциях (Ванадзор, Ташир) обнаружены положительные линии трендов годовой суммы атмосферных осадков. Обнаруженные тенденции изменения количества осадков по сравнению с тенденциями изменения температуры воздуха имеют более низкую статистическую значимость 
и менее устойчивы. Тенденция роста количества выпадающих осадков наблюдается и в других регионах.

В статье представлены многолетние изменения среднегодовой температуры воздуха $(\mathrm{a}, \sigma)$ и годовой суммы атмосферных осадков (в, г) для метеостанций, находящихся на разных высотах: Ванадзор - 1376 м, Одзун - 1105 м (рис. 4). Как видно из рисунка 4 на метеостанции Одзун за период 1964-2018 годы скорость годового потепления $\left(+0,288^{\circ} \mathrm{C} / 10\right.$ лет) уступает скорости годового потепления $\left(+0,368{ }^{\circ} \mathrm{C} / 10\right.$ лет) на метеостанции
Ванадзор. В отличие от температуры воздуха, на метеостанции Одзун обнаружено уменьшение годовой суммы осадков и их увеличение на метеостанции Ванадзор. Скорость изменения суммы атмосферных осадков соответственно составляет $-13,3$ мм/10 лет и $+10,2$ мм/10 лет. В среднем с 1964 по 2018 год на метеостанции Одзун годовая температура воздуха повысилась на $1,6^{\circ} \mathrm{C}$, а годовая сумма атмосферных осадков уменьшилась на 73,2 мм. На метеостанции Ванадзор годовая температура воздуха повысилась на $2,0^{\circ} \mathrm{C}$, а годовая сумма атмосферных осадков - на 56,1 мм.

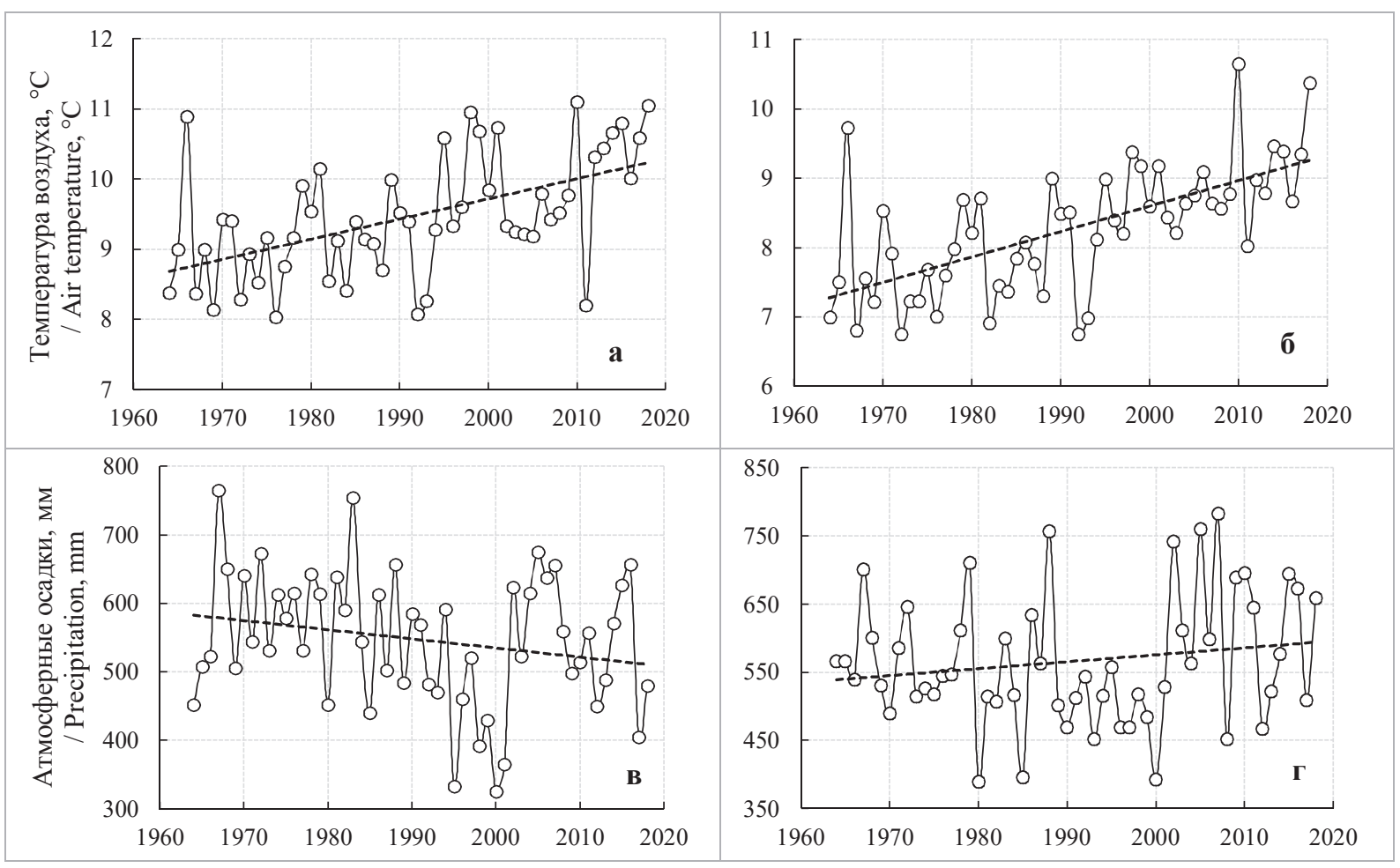

Puc. 4. Многолетние изменения среднегодовой температуры воздуха $(\mathbf{a}, \boldsymbol{\sigma})$

и годовой суммы атмосферных осадков (в, г) в бассейне р. Дебед для метеостанций на разных высотах: Одзун - 1105 м (а, в), Ванадзор - 1376 м (б, г)

[Fig. 4. Long-term changes in the average annual air temperature $(\mathrm{a}, \mathrm{b})$ and the annual amount of atmospheric precipitation $(c, d)$ in the Debed River basin for weather stations at different heights: Odzun - 1105 m (a, c), Vanadzor - 1376 m (b, d) ]

Нами выявлено, что есть некоторая связь между изменением среднегодовой температуры воздуха и абсолютной высотой местности. На обсуждаемой территории до высоты 500 м изменения среднегодовой температуры воздуха составляют $2,3-2,4{ }^{\circ} \mathrm{C}$, с высоты 500 м до $1500 \mathrm{~m}-1,4-1,5^{\circ} \mathrm{C}$, а выше 1500 метров - менее $1,5^{\circ} \mathrm{C}$. Для изменения годовой суммы атмосферных осадков такая закономерность не обнаружена. Свидетельством этому является то обстоятельство, что изменения количества осадков преимущественно связаны с локальными особенностями.
Таким образом, изучение основных климатических характеристик (годовая температура воздуха и количество осадков) и их временных колебаний дает возможность получить данные, актуальные для регионального территориального планирования с целью эффективного использования и освоения потенциала водно-тепловых ресурсов бассейна реки Дебед.

Формирование речного стока, а также его внутригодовое распределение тесно связано с климатическими условиями данной территории, в особенности, с пространственно-временными особен- 
ностями температуры воздуха и осадков. Поэтому для выявления внутригодового распределения речного стока необходимо подробно изучить особенности распределения температуры воздуха и атмосферных осадков во времени и пространстве.

\section{ВЫВОДЫ}

В результате исследований пришли к следующим выводам.

1. На изучаемой территории типично неравномерное распределение температуры воздуха и осадков: среднегодовая температура воздуха колеблется в пределах от $3,7^{\circ} \mathrm{C}$ до $12,3{ }^{\circ} \mathrm{C}$, а годовое количество осадков - от 462 мм по 770 мм.

2. С высотой местности понижается температура воздуха и увеличивается количество осадков: вертикальный градиент соответственно составляет $0,5^{\circ} \mathrm{C} / 100$ м и $-20 \mathrm{~mm} / 100 \mathrm{~m}$.

3. В бассейне реки Дебед в целом за последние 55 лет многолетние колебания среднегодовой температуры воздуха характеризуются положительными, а многолетние колебания годовой суммы атмосферных осадков - отрицательными трендами.

4. В среднем по бассейну реки Дебед с 1964 по 2018 годы температура воздуха повысилась на $1,7^{\circ} \mathrm{C}$, а годовая сумма атмосферных осадков уменьшилась на 6 мм. Значительный рост годовых температур наблюдается особенно после 1990-х годов - на $1,0{ }^{\circ} \mathrm{C}$.

5. С высотой местности понижается изменение среднегодовой температуры воздуха - от 2,3$2,4{ }^{\circ} \mathrm{C}\left(500\right.$ м) до $1,5^{\circ} \mathrm{C}$ и менее (выше 1500 м).

\section{СПИСОК ЛИТЕРАТУРЫ}

1. Абдулжалимов А.А., Атаев 3.В., Братков В.В. Современные климатические изменения высокогорных ландшафтов Северо-Восточного Кавказа // Известия Дагестанского государственного педагогического университета. Естественные и точные науки, 2015, № 2, c. 86-94.

2. Акимов Л.М., Задорожная Т.Н. Особенности распределения трендов температуры воздуха на Европейской территории России и сопредельных государств // Вестник ВГУ. Серия: География. Геоэкология, 2018, № 4, с. 5-14. DOI: https://doi.org/10.17308/ geo.2018.4/2260

3. Атаев 3. В., Братков В.В. Реакция ландшафтов Северного Кавказа на современные климатические изменения // Юг России: экология, развитие, 2014, № 1, c. 141-157.

4. Бардин М.Ю., Платова Т.В., Самохина О.Ф. Особенности наблюдаемых изменений климата на территории Северной Евразии по данным регулярного мониторинга и возможные их факторы // Труды гидроме- теорологического научно-исследовательского центра Российской Федераичи, 2015, вып. 358, с. 13-35.

5. Груза Г.В., Ранькова Э. Я. Наблюдаемыле и ожидаемые изменения климата России: температура воздуха. Обнинск: ФГБУ «ВНИИГМИ-МЦД», 2012. 194 с.

6. Кириллина К.С., Лобанов В.А. Оценка современных климатических изменений температуры воздуха на территории республики Саха (Якутия) // Ученые записки РГГМУ, 2015, №38, с. 137-151.

7. Климатический справочник. Ч. І. Температура воздуха и почвы. Ереван, 2011. 150 с. (на армянском яз.).

8. Климатический справочник. Часть II. Влажность воздуха, атмосферные осадки и снежный покров. Ереван, 2012. 172 с. (на армянском языке).

9. Кошелева О.Ю., Шинкаренко С.С., Гордиенко О.А., Дубачева А.А., Омаров Р.С. Суточная и сезонная динамика температуры поверхности города Волгограда // Вестник ВГУ. Серия: География. Геоэкология, 2021, № 1, c. 14-24. DOI: https://doi.org/10.17308/ geo.2021.1/3252

10. Лобанов В.А., Маммедов С.А. Оценка климатических изменений температуры воздуха и их устойчивости на территории центральной Азии // Ученые записки РГГМУ, 2018, №51, с. 22-36.

11. Лобанов В.А., Шадурский А.Е. Применение эмпирико-статистических методов для моделирования и анализа климатических изменений // Ученье записки РГГМУ, 2010, № 14, с. 73-88.

12. Локощенко М.А., Исаев А.А. О вековых изменениях годового количества осадков в г. Москве // Вестник Московского университета. Серия 5: География, 2004, № 5, с. 42-46.

13. Маргарян В.Г., Самвелян Н.И. Закономерности пространственно-временного изменения экстремальных температур приземного слоя атмосферы и их воздействие на ландшафтную структуру Араратской котловины // Вестник ВГУ. Серия: География. Геоэкология, 2019, № 4, с. 15-22. DOI: doi.org/10.17308/ geo.2019.4/2707

14. Переведенцев Ю. П., Шарипова Р. Б. Изменение основных климатических показателей на территории Ульяновской области // Вестник Удмуртского университета. Серия: Биология. Науки о Земле, 2012, вып. 1, c. $136-144$.

15. Токарчук С.М., Янчук Я.Г. Основные климатические характеристики г. Бреста и особенности их изменения: сравнительно-географический аспект // Псковский регионологический журнал, 2015, № 24, с. 59-71.

16. Amiranashvili A., Matcharashvili T., Chelidze T. Climate Change in Georgia; statistical and nonlinear dynamics predictions // Journal of Georgian Geophysical Society, Issue (A), Physics of Solid Earth, 2011-2012, vol. 15a, pp. 67-87.

17. Armenia's fourth national communication on climate change, 2020. 213 p.

18. Building Resilience to Climate Change in South Caucasus Agriculture / Nicolas Ahouissoussi, James E. 
Neumann, and Jitendra P. Srivastava, Editors. International Bank for Reconstruction and Development. 2014. 167 p. DOI: https://doi.org/10.1596/978-1-4648-0214-0.

19. IPCC (Intergovernmental Panel on Climate Change: Climate Change). 2013. The physical science basis. In Contribution of Working Group I to the Firth Assessment Report of the Intergovernmental Panel on Climate Change, Thomas F. Stocker, Dahe Qin, Gian-Kasper Plattner, Melinda M.B. Tignor, Simon K. Allen, Judith Boschung, Alexander Nauels, Yu Xia, Vincent Bex, Pauline M. Midgley (eds). Cambridge: Cambridge University Press. $1552 \mathrm{p}$.

20. Margaryan V., Klimenko V., Cherkashina N. Specific changes in main climatic characteristics of the Debed river basin (armenia) // Vestnik of V.N. Karazin Kharkiv National University, series «Geology. Geography. Ecology», 2021, no. 54, pp. 195-205.

21. Margaryan V., Tsibulskii G., Raevich K. About the features of the time course of the average annual air temperature in the territory of the Debed river basin (Armenia) // E3S Web of Conferences, 2020, vol. 223, id. 03009. Regional Problems of Earth Remote Sensing (RPERS 2020).

Конфликт интересов: Автор декларирует отсутствие явных и потенциальных конфликтов интересов, связанных с публикацией настоящей статьи.

Поступила в редакцию 16.06.2021

Принята к публикаџии 23.11.2021

\title{
Main Climatic Characteristics and Peculiarities of Their Changes in the Debed River Basin Area
}

\author{
V.G. Margaryan $\bowtie$ \\ Yerevan State University, Armenia \\ (1, Alek Manukyan Str., Yerevan, 0025)
}

\begin{abstract}
The purpose of the study is to analyze the patterns of time fluctuations in the main climatic characteristics (annual temperature air and precipitation) of the Debed River basin.

Materials and methods. The article used the methods of mathematical and statistical, extrapolation, analysis, analogy, correlation, cartographic. As a baseline, data from actual observations of surface air temperature and precipitation in the Debed River basin on the territory of Armenia were used. The study was performed on 6 meteorological stations of the Debed River in long rows observational data from the mid-1960s. to 2018.

Results and discussion. A close correlation between annual values of air temperature and precipitation was obtained, which can be used in the study area of the basin. The intra-annual distribution of air temperature, precipitation and river runoff, changes in mean annual air temperature and precipitation for both the entire Debed River basin area and for each of the meteorological stations currently in operation are presented.

Conclusions. There is considerable variability in the average annual surface temperature and annual precipitation in the Debed River basin. There is a widespread upward trend in average annual air temperature and a predominantly downward trend in annual precipitation. Some weather stations are showing an upward trend in precipitation. With the absolute altitude of the terrain, a decrease in the average annual air temperature is found.
\end{abstract}

Key words: Debed River basin, air temperature, precipitation, long-term changes, trend.

Financing: This work was supported by the RA Science Committee and Russian Foundation for Basic Research $(R F)$ in the frames of the joint research project SCS 20RF-039 Short-term probabilistic forecast of river flow during the spring flood and RFBR № 20-55-05006\20 accordingly.

Acknowledgments. The author is grateful to Dr. Mikhail Alexandrovich Lokoshchenko (Lomonosov Moscow State University) for the consultation.

For citation: Margaryan V. G. Main Climatic Characteristics and Peculiarities of Their Changes in the Debed River Basin Area. Vestnik Voronezskogo gosudarstvennogo universiteta. Seria: Geografia. Geoekologia, 2021, no. 4, pp. 22-33. (In Russ.) DOI: https://doi.org/10.17308/geo.2021.4/3747

(C) Margaryan V.G., 2021

\Vardui G. Margaryan, e-mail: vmargaryan@ysu.am

The content is available under Creative Commons Attribution 4.0 License. 


\section{REFERENCE}

1. Abdulzhalimov A.A., Ataev Z.V., Bratkov V. V. Sovremennyye klimaticheskiye izmeneniya vysokogornykh landshaftov Severo-Vostochnogo Kavkaza [Modern climate changes of high-mountain landscapes of the North-Eastern Caucasus]. Izvestiya Dagestanskogo gosudarstvennogo pedagogicheskogo universiteta. Yestestvennyye $i$ tochnyye nauki, 2015, no. 2, pp. 86-94. (In Russ.)

2. Akimov L.M., Zadorozhnaya T.N. Osobennosti raspredeleniya trendov temperatury vozdukha na Yevropeyskoy territorii Rossii i sopredel'nykh gosudarstv [Features of distribution of air temperature trends in the European areas of Russia and adjacent countries]. Vestnik VGU. Seriya: Geografiya. Geoekologiya, 2018, no. 4, pp. 5-14. (In Russ.) DOI: https://doi.org/10.17308/geo.2018.4/2260

3. Atayev Z.V., Bratkov V.V. Reaktsiya landshaftov Severnogo Kavkaza na sovremennyye klimaticheskiye izmeneniya [Reaction of landscapes of the North Caucasus on the current climatic changes]. Yug Rossii: ekologiya, razvitiye, 2014, no. 1, pp. 141-157. (In Russ.)

4. Bardin M.Yu., Platova T.V., Samokhina O.F. Osobennosti nablyudayemykh izmeneniy klimata na territorii Severnoy Yevrazii po dannym regulyarnogo monitoringa i vozmozhnyye ikh faktory [Features of observed climate changes on the territory of Northern Eurasia according to regular monitoring data and their possible factors]. Trudy FGBU «Gidromettsentr Rossii», 2015, issue 358, pp. 13-35. (In Russ.)

5. Gruza G. V., Rankova E. Ya. Nablyudayemyye i ozhidayemyye izmeneniya klimata Rossii: temperatura vozdukha [Observed and expected climate changes over Russia: surface air temperature]. Obninsk: «VNIIGMI-MTSD», 2012. 194 p. (In Russ.)

6. Kirillina K. S., Lobanov V.A. Otsenka sovremennykh klimaticheskikh izmeneniy temperatury vozdukha na territorii respubliki Sakha (Yakutiya) [Assessment of modern climatic changes of air temperature in the territory of the Republic of Sakha (Yakutia)]. Izvestiya Rossiyskogo gosudarstvennogo gidrometeorologicheskogo universiteta (RGGMU), 2015, no. 38, pp. 137-151. (In Russ.)

7. Klimaticheskiy spravochnik [Climate guide]. Part 1. Air and soil temperature. Yerevan, 2011. 150 p. (In Armenian)

8. Klimaticheskiy spravochnik [Climate guide]. Part II. Air humidity, precipitation and snow cover. Yerevan. 2012. 172 p. (In Armenian)

9. Kosheleva O.Yu., Shinkarenko S.S., Gordienko O.A., Dubacheva A.A., Omarov R.S. Sutochnaya i sezonnaya dinamika temperatury poverkhnosti goroda Volgograda [Daily and Seasonal Dynamics of Surface Temperature in the Volgograd City]. Vestnik Voronezskogo gosudarstvennogo universiteta. Seria: Geografia. Geoekologia, 2021, no. 1, pp. 14-24. (In Russ.) DOI: https://doi.org/10.17308/ geo.2021.1/3252

10. Lobanov V.A., Mammedov S.A. Otsenka klimaticheskikh izmeneniy temperatury vozdukha i ikh ustoychivosti na territorii tsentral'noy Azii [Assessment of climatic changes in air temperature and their stability in Central
Asia]. Izvestiya Rossiyskogo gosudarstvennogo gidrometeorologicheskogo universiteta (RGGMU), 2018, no. 51, pp. 22-36. (In Russ.)

11. Lobanov V.A., Shadursky A.E. Primeneniye empiriko-statisticheskikh metodov dlya modelirovaniya i analiza klimaticheskikh izmeneniy [Application of empiric-statistical methods for modeling and analysis of climatic changes]. Izvestiya Rossiyskogo gosudarstvennogo gidrometeorologicheskogo universiteta (RGGMU), 2010, no. 14. P. 73-88. (In Russ.)

12. Lokoshchenko M.A., Isaev A. A. O vekovykh izmeneniyakh godovogo kolichestva osadkov v g. Moskve [Centennial changes in the annual amounts of precipitation in Moscow]. Vestnik Moskovskogo universiteta. Seriya 5. Geografiya, 2004, no. 5, pp. 42-46. (In Russ.)

13. Margaryan V. G., Samvelyan N. I. Zakonomernosti prostranstvenno-vremennogo izmeneniya ekstremal'nykh temperatur prizemnogo sloya atmosfery i ikh vozdeystviye na landshaftnuyu strukturu Araratskoy kotloviny [The regularities of spatial and temporal change of extremal temperatures of earth layer of atmosphere and its influence on the environment Ararat valley hollow]. Vestnik Voronezskogo gosudarstvennogo universiteta. Seria: Geografia. Geoekologia, 2019, no. 4, pp. 15-22. (in Russ.). DOI: https://doi.org/10.17308/geo.2019.4/2707

14. Perevedentsev Yu.P., Sharipova R. B. Izmeneniye osnovnykh klimaticheskikh pokazateley na territorii Ul'yanovskoy oblasti [Change of the basic climate indicators in the territory of the Ulyanovsk region]. Vestnik $U d$ murtskogo universiteta. Seriya: Biologiya. Nauki o Zemle, 2012, issue. 1, pp. 136 -144. (In Russ.)

15. Tokarchuk S., Yanchuk Y. [General climatic characteristics of Brest and features of their changes: comparative-geographical aspect]. Pskovskiy regionologicheskiy zhurnal, 2015, no. 24, pp. 59-71. (In Russ.)

16. Amiranashvili A., Matcharashvili T., Chelidze T. Climate Change in Georgia; statistical and nonlinear dynamics predictions. Journal of Georgian Geophysical Society, issue (A), Physics of Solid Earth, vol. 15a, 20112012, pp. 67-87.

17. Armenia's fourth national communication on climate change. 2020.213 p.

18. Building Resilience to Climate Change in South Caucasus Agriculture / Nicolas Ahouissoussi, James E. Neumann, and Jitendra P. Srivastava, Editors. International Bank for Reconstruction and Development. 2014. 167 p. DOI: https://doi.org/10.1596/978-1-4648-0214-0.

19. IPCC (Intergovernmental Panel on Climate Change: Climate Change). 2013. The physical science basis. In Contribution of Working Group I to the Firth Assessment Report of the Intergovernmental Panel on Climate Change, Thomas F. Stocker, Dahe Qin, Gian-Kasper Plattner, Melinda M.B. Tignor, Simon K. Allen, Judith Boschung, Alexander Nauels, Yu Xia, Vincent Bex, Pauline M. Midgley (eds). Cambridge: Cambridge University Press. 1552 p.

20. Margaryan V., Klimenko V., Cherkashina N. Specific changes in main climatic characteristics of the Debed river basin (armenia). Vestnik of V.N. Karazin Kharkiv Na- 
tional University, series: Geology. Geography. Ecology, 2021, no. 54, pp. 195-205.

21. Margaryan V., Tsibulskii G., Raevich K. About the features of the time course of the average annual air temperature in the territory of the Debed river basin (Armenia). E3S Web of Conferences, 2020, vol. 223, id. 03009. Regional Problems of Earth Remote Sensing (RPERS 2020).

\section{Маргарян Вардуи Гургеновна}

Кандидат географических наук, доцент кафедры физической географии и гидрометеорологии географического и геологического факультета Ереванского государственного университета, г. Ереван, Армения, ORCID: 0000-0003-3498-0564, e-mail: vmargaryan@ysu.am
Conflict of interests: The author declares no information of obvious and potential conflicts of interest related to the publication of this article.

Received: 16.06.2021 Accepted: 23.11.2021

Vardui G. Margaryan

Cand. Sci. (Geogr.), Associate Professor of the Department of Physical Geography and Hydrometeorology, Geography and geology Faculty, Yerevan State University, Yerevan, Armenia, ORCID: 0000-0003-3498-0564, e-mail: vmargaryan@ysu.am 